\title{
Physical activity and energy balance
}

\author{
Marleen A. van Baak* \\ Department of Human Biology, Maastricht University, P.O.Box 616, 6200 MD Maastricht, The Netherlands
}

Accepted 7 May 1999

\begin{abstract}
Energy expenditure rises above resting energy expenditure when physical activity is performed. The activity-induced energy expenditure varies with the muscle mass involved and the intensity at which the activity is performed: it ranges between 2 and 18 METs approximately. Differences in duration, frequency and intensity of physical activities may create considerable variations in total energy expenditure. The Physical Activity Level (= total energy expenditure divided by resting energy expenditure) varies between 1.2 and 2.2-2.5 in healthy adults. Increases in activity-induced energy expenditure have been shown to result in increases in total energy expenditure, which are usually greater than the increase in activity-induced energy expenditure itself. No evidence for increased spontaneous physical activity, measured by diary, interview or accelerometer, was found. However, this does not exclude increased physical activity that can not be measured by these methods. Part of the difference may also be explained by the post-exercise elevation of metabolic rate.

If changes in the level of physical activity affect energy balance, this should result in changes in body mass or body composition. Modest decreases of body mass and fat mass are found in response to increases in physical activity, induced by exercise training, which are usually smaller than predicted from the increase in energy expenditure. This indicates that the training-induced increase in total energy expenditure is at least partly compensated for by an increase in energy intake. There is some evidence that the coupling between energy expenditure and energy intake is less at low levels of physical activity. Increasing the level of physical activity for weight loss may therefore be most effective in the most sedentary individuals.
\end{abstract}

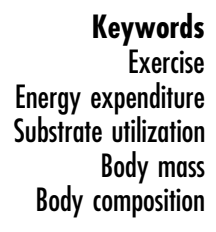

\section{Key messages}

- Regular exercise increases total daily energy expenditure.

- Energy intake is better balanced to energy expenditure at moderate to high levels of physical activity than at low (or very high) levels of physical activity.

- A moderate to high level of physical activity reduces the risk of weight (re)gain and obesity.

\section{Introduction}

A high $\left(>25 \mathrm{~kg} \mathrm{~m}^{-2}\right)$ and a low $\left(<18.5 \mathrm{~kg} \mathrm{~m}^{-2}\right)$ body mass index (BMI) are both associated with increased health risks. Though low BMI is an important health risk in many underdeveloped and developing countries, in most European countries excess storage of body fat or obesity forms the major BMI-related health burden. The main overweight- and obesity-related health risks are non-insulin dependent diabetes, gallstones, dyslipidaemia, coronary heart disease, hypertension and osteoarthritis. The health risk increases with increasing levels of body fat. A more abdominal distribution of body fat further increases risk. Prevention of weight gain during the adult life and weight loss in those overweight has been shown to be associated with lower health risks.

Storage of energy in the form of body fat occurs in situations of a positive energy balance, i.e. when more energy is ingested than expended. This paper will focus on energy expenditure and especially the variations in energy expenditure that can be introduced by physical activity. Thereafter, the effects of variations in physical activity on energy balance will be discussed.

\section{Energy cost of physical activities}

Total daily energy expenditure (TEE) can be subdivided into three components: resting energy expenditure (REE), diet-induced energy expenditure (DEE) and activity-induced energy expenditure (AEE). REE is the energy expended to maintain normal body functions and homeostasis. DEE includes the energy costs of food absorption, metabolism and storage. AEE includes the energy expenditure during voluntary physical activity and involuntary activities, such as shivering, fidgeting and postural control. On average REE and 
DEE together determine $70-85 \%$ of TEE, whilst AEE is responsible for the remainder of the energy expended over $24 \mathrm{~h}$. Variations in REE, adjusted for body composition, and DEE between individuals are relatively small and do not appear to contribute importantly to variations in energy balance ${ }^{1}$. However, AEE may vary considerably between individuals. Duration and intensity of activities may vary. During different types of physical activities metabolic rate may vary approximately 9-fold, ranging from 2 METs (slow pace walking, strolling) to 18 METs (competitive crosscountry skiing, running, cycling) ${ }^{2}$. The MET unit denotes multiples of resting metabolic rate associated with the activity. The energy cost of household (2-9 METs) and occupational activities (2-17 METs) may also vary considerably ${ }^{2}$, although the duration of the most intense activities, if performed at all, is usually very limited in western societies.

\section{Substrate utilization during exercise}

At low exercise intensities (25\% of maximal oxygen uptake $\left(V_{\mathrm{O}_{2 \max }}\right)$, which in an average healthy untrained young adult $\left(V_{\mathrm{O}_{2 \max }}\right.$ per $\mathrm{kg}$ body mass = $42 \mathrm{ml} \mathrm{kg}^{-1} \mathrm{~min}^{-1}$ ) corresponds with level walking at $4-$ $5 \mathrm{~km} \mathrm{~h}^{-1}$, the energy is almost completely provided by oxidation of fatty acids of which more than $85 \%$ is derived from plasma ${ }^{3,4}$. At $85 \%$ of $V_{\mathrm{O}_{2 \max }}$, corresponding with running at approximately $9 \mathrm{~km} \mathrm{~h}^{-1}$ or cycling at approximately $24 \mathrm{~km} \mathrm{~h}^{-1}$, less than $30 \%$ of the energy is derived from oxidation of fatty acids and approximately half of the fatty acid oxidation is derived from oxidation of plasma free fatty acids. At this intensity the majority of the energy comes from muscle glycogen. Therefore with increasing exercise intensity a shift from the relative utilization of fats to carbohydrates and from plasma derived substrates to intramuscular substrates is seen. The largest absolute fat oxidation is seen during low and moderate intensity exercise. These data have been collected in endurance-trained subjects under fasting conditions after approximately $30 \mathrm{~min}$ of exercise. More recent studies suggest that the contribution of plasma free fatty acids to total fat oxidation is probably underestimated, especially at low exercise intensity, because label fixation in the tricarboxylic acid-cycle has not been taken into account ${ }^{5,6}$. With more prolonged exercise the contribution of fat oxidation will increase at the cost of carbohydrate oxidation $^{4}$. Less well-trained individuals will usually oxidize less fat and will utilize more muscle glycogen at a given percentage of $V_{\mathrm{O}_{2 \max }}$. Moreover, pre-exercise carbohydrate feedings may reduce fat oxidation and increase carbohydrate oxidation during exercise, while high fat diets may increase fat oxidation but do not lower glycogen utilization ${ }^{4,7}$. Carbohydrate feedings during exercise will increase carbohydrate oxidation ${ }^{8}$, although muscle glycogen utilization is unchanged ${ }^{9}$.

\section{Physical activity and $24 \mathrm{~h}$ energy expenditure}

As discussed above, physical activity increases energy expenditure and the contribution of fat oxidation to energy expenditure is most pronounced during low and moderately intense activities. Differences in duration, frequency and intensity of physical activities may create considerable variations in TEE. Studies using the doubly-labelled water technique have shown that the Physical Activity Level (PAL: TEE/REE) varies between 1.2 and $2.2-2.5$ in free-living healthy adults between 18 and 64 years from affluent western societies, although under extreme conditions, for instance in elite athletes (runners, cross-country skiers and professional cyclists), PAL values $>2.5$ were found ${ }^{10,11}$. A regular, relatively sedentary, adult western professional lifestyle appears to be associated with a PAL of $1.55-1.65^{10}$.

It cannot automatically be assumed that changes in AEE will cause TEE to change by the same amount as the change in AEE. A small number of longitudinal studies, applying the doubly-labelled water methodology to measure TEE, has investigated this issue ${ }^{12-17}$. The increase in TEE due to an exercise training programme was only $3 \%$ in the study by Goran and Poehlman ${ }^{15}$ in elderly men and was highest (27\%) in the study by Bingham et al. ${ }^{12}$. In the latter study, however, physical activity was restricted to approximately $15 \mathrm{~min} / \mathrm{d}$ in the non-training control period. Van Etten et al. ${ }^{17}$ noted that, with the exception of the study in elderly men ${ }^{15}$, the increase in TEE was always higher than the energy cost of the exercise intervention itself (Fig. 1). The reason for this difference is not fully clear.

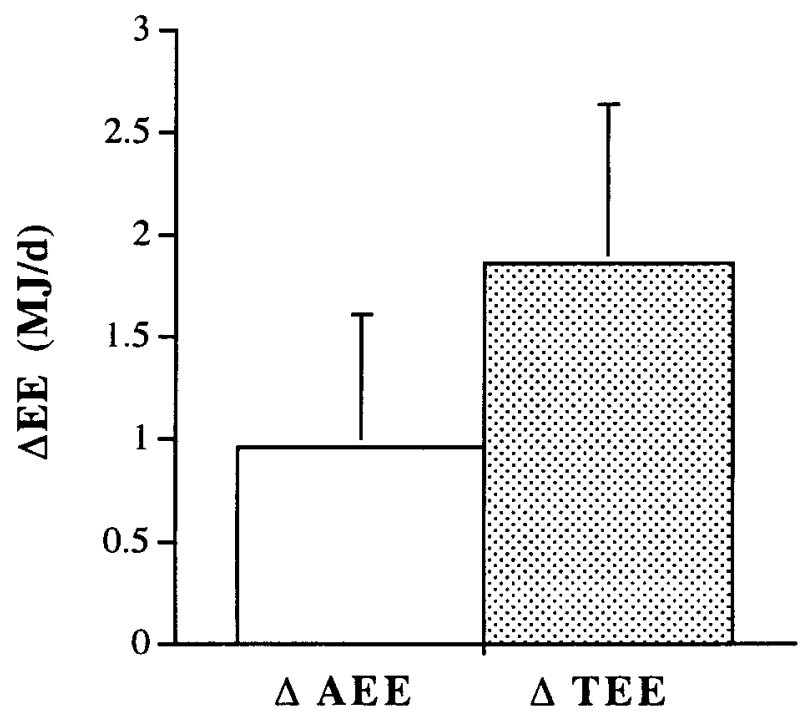

Fig. 1 Changes in activity-induced energy expenditure (AEE) and total $24 \mathrm{~h}$ energy expenditure (TEE) during a training programme (mean \pm SD). Based on references 12, 13, 14 and 17 
Longitudinal training studies in majority show no effect on REE measured between 12 and $96 \mathrm{~h}$ after the last training session ${ }^{11,18}$. DEE also does not seem to be affected by exercise training ${ }^{19-21}$, although the data are not fully consistent ${ }^{18}$. This suggests that either the excess post-exercise oxygen consumption (EPOC) associated with the exercise bouts or increased nontraining physical activity (or a combination) are responsible for the extra rise in TEE. Energy expenditure may remain elevated for some time during recovery from exercise. Estimations of this increased energy expenditure or EPOC vary between 125 and $625 \mathrm{~kJ}$, depending on the duration and intensity of exercise $^{18,22,23}$, but total EPOC is always smaller then the amount of energy expended during the exercise bout itself. EPOC can therefore not fully explain the excess increase in TEE. Westerterp ${ }^{11}$ reviewed the available data on spontaneous physical activity in these studies and concluded that the exercise interventions did not change spontaneous physical activity except in elderly men where spontaneous activity was reduced. However, since spontaneous activity was assessed by diary, interview or accelerometer, increases in other physical activities that can not be measured by these methods (e.g. fidgeting, activities causing nonexercise-activity thermogenesis ${ }^{24-26}$ ) may have been missed.

\section{Physical activity and $24 \mathrm{~h}$ substrate utilization}

The question whether changes in level of physical activity lead to changes in $24 \mathrm{~h}$ substrate utilization has hardly been studied. During the first hours after an exercise bout fat oxidation appears to be increased ${ }^{27,28}$. Resting fat oxidation, measured at least $36 \mathrm{~h}$ after the last exercise bout, also was found to be increased after an exercise training programme ${ }^{29,30}$. However, the effect of increased physical activity on $24 \mathrm{~h}$ substrate utilization has not been studied, except in post-obese women ${ }^{31}$. In this study no change in $24 \mathrm{~h} \mathrm{RQ}$, measured in a respiration chamber, was found after a training programme. Further studies are needed to elucidate the effect of endurance training on $24 \mathrm{~h}$ substrate utilization. Resulting from methodological restraints, such studies will be limited to measurements in respiration chambers and thus will only partly reflect real life.

\section{Resistance exercise}

The studies reviewed above all used endurance type of exercise training. Much less information is available about the effect of resistance type of exercise on TEE and substrate utilization. Poehlman and Melby ${ }^{32}$ have recently reviewed these studies and conclude that resistance training may elevate REE, but does not substantially enhance TEE in free-living subjects. Intense resistance exercise may increase EPOC and shift substrate oxidation to a greater reliance on fat oxidation. The effect of resistance training on $24 \mathrm{~h}$ substrate has only been measured in one study, under respiration chamber conditions ${ }^{33}$. This study showed that $24 \mathrm{~h}$ fat oxidation was significantly increased by resistance training, independent of changes in $24 \mathrm{~h}$ energy expenditure. Further studies are needed to confirm this finding.

\section{Physical activity and energy balance}

As indicated above, available data suggest that TEE increases with increasing physical activity. Increasing the level of physical activity therefore has the potential to affect energy balance, but the question whether it does depends on the compensatory changes in macronutrient and energy intake.

If changes in level of physical activity affect energy balance, this should result in changes in body weight or body composition. Westerterp ${ }^{11}$ has reviewed the body mass and body composition changes in the studies mentioned above, which applied the doubly-labelled water technique to measure changes in TEE during an exercise training intervention. The increase in TEE in these studies varied between 1.2 and $2.8 \mathrm{MJ} / \mathrm{d}$. If no energy intake compensation had occurred this increase would lead to a considerable decrease of fat mass (1-3 kg per month). However, no significant weight loss was found in any of these studies, which varied in duration between 4 and 40 weeks. A significant increase in fat-free mass was found in all studies, which was accompanied by a significant decrease in fat mass in part of the studies. Wilmore ${ }^{34}$ reviewed a total of 53 endurance training studies. He concluded that a 6-month training period reduced body mass by on average $1.6 \mathrm{~kg}$, fat mass by $2.6 \mathrm{~kg}$ and increased fat-free mass by $1.0 \mathrm{~kg}$. Garrow and Summerbell ${ }^{35}$ did a metaanalysis on endurance training interventions in overweight individuals and found an average weight loss of $3 \mathrm{~kg}$ over 30 weeks in men and $1.4 \mathrm{~kg}$ over 12 weeks in women. Although the amount of training may not have been completely comparable in the different reviews, these result at least suggest that less body mass is lost during the interventions then might be expected from the training-induced increase in TEE. Apparently, the training-induced increase in TEE is at least partly compensated for by an increase in energy intake.

This is not unexpected. Already the classical studies by Mayer et al. ${ }^{36,37}$ in rats and in humans indicated a close coupling between level of physical activity and energy intake over a wide range of physical activities. Over this range body mass is maintained at a constant lean level. In very sedentary individuals this tight coupling is lost and energy intake is inappropriately 
high, resulting in increased body weight. Several large cross-sectional and longitudinal studies have indeed shown that average body mass or fat mass increases with decreasing levels of physical activity and that weight gain is associated with low or decreasing physical activity ${ }^{38-41}$. The study by Haapanen et $a l^{41}$, for instance, showed that in a group of over 5000 working-aged Finnish men and women, the risk of clinically significant body mass gain ( $>5 \mathrm{~kg}$ during the 10-year follow-up) was higher in men and women who decreased their physical activity during the follow-up period or were inactive all the time than in subjects who were active all the time.

The results obtained by Mayer ${ }^{37}$ also predict that there is a threshold of physical activity below which body mass is no longer maintained at the lean level. Schoeller ${ }^{42}$ has recently addressed this issue and concluded from cross-sectional studies, using the doubly-labelled water technique to measure TEE, that such a threshold indeed appears to be present in men: the least active group of men that did not tend to have increased levels of overweight was the moderate activity group with a physical activity level (TEE/REE) of 1.66 to 1.9 (Fig. 2). In women the picture is less clear: as in men, average BMI is higher in women with light compared to moderate physical activity, but in the most sedentary group of women BMI is lower then in any other physical activity group. This may suggest that body weight regulation in response to physical activity is different in men and women, although

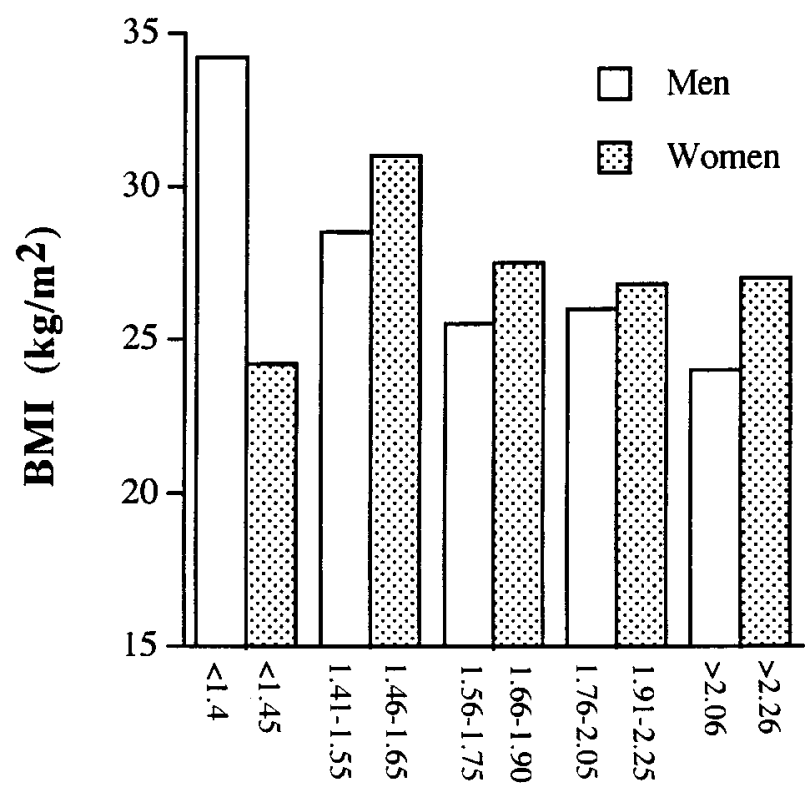

PAL categories

Fig. 2 Relation between level of physical activity (PAL: TEE/REE) and body mass index (BMI) in men and women. Adapted from Schoeller ${ }^{42}$ methodological bias as a cause of this gender difference cannot be excluded. This issue clearly needs further study.

Schoeller ${ }^{42}$ also demonstrated that in post-obese women the spontaneous increase in body weight was larger in women with a low physical activity than in women with a higher level of physical activity. There was substantial variation in spontaneous weight gain especially in those women with low physical activity (TEE/REE < 1.75). Other data also support the notion that regular exercise may help to maintain body mass loss ${ }^{43,44}$, though the presence of a threshold level of physical activity has not been addressed in these studies.

The data presented above indicate that a moderate or high level of physical activity protects against weight gain in the lean. In the sedentary overweight individual, increased physical activity may help to decrease body mass. Remaining at least moderately active after weight reduction will help to maintain a lower body weight. These effects of physical activity are seen against the background of the western diet with a relatively high energy density and high fat content. It remains to be demonstrated whether variations in the energy and fat content of the diet will change the threshold physical activity for maintenance of lean body weight. A study by Stubbs et $a l .{ }^{45}$ showing that individuals are more able to maintain (short-term) energy balance on a high fat diet when they are free-living than when they are confined to a respiration chamber, indicates that such an interaction may indeed be present.

\section{References}

1 Weinsier RL, Hunter GR, Heini AF, Goran MI, Sell SM. The etiology of obesity: relative contribution of metabolic factors, diet, and physical activity. Am. J. Med. 1998; 105 $145-50$

2 Ainsworth BE, Haskell WL, Leon AS, Jacobs DR, Montoye HJ, Sallis JF, Paffenbarger Jr RS. Compendium of physical activities: classification of energy costs of human physical activities. Med. Sci. Sports Exerc. 1993; 25: 71-80.

3 Romijn JA, Coyle EF, Sidossis L et al. Regulation of endogenous fat and carbohydrate metabolism in relation to exercise intensity. Am. J. Physiol. 1993; 265: E380-91.

4 Coyle EF. Substrate utilization during exercise in active people. Am. J. Clin. Nutr. 1995; 61(suppl): 968S-79S.

5 Sidossis LS, Coggan AR, Gastaldelli A, Wolfe RR. A new correction factor for use in tracer estimations of plasma fatty acid oxidation. Am. J. Physiol. 1995; 269: E649-56.

6 Schrauwen P, van Aggel-Leijssen DPC, van Marken Lichtenbelt WD, van Baak MA, Gijsen AP, Wagenmakers AJM. Validation of the $\left[1,2-{ }^{13} \mathrm{C}\right]$ acetate recovery factor for correction of $\left[\mathrm{U}-{ }^{13} \mathrm{C}\right]$ palmitate oxidation rates in humans. J. Physiol. 1998 ; 513.1: $215-23$.

7 Hawley JA, Brouns F, Jeukendrup A. Strategies to enhance fat utilisation during exercise. Sports Med. 1998; 25: 241-57.

8 Wagenmakers AJM, Brouns F, Saris WHM, Halliday D. Oxidation rates of orally ingested carbohydrates during prolonged exercise in men.J. Appl. Physiol. 1993; 75: 2774-80.

9 Coggan AR, Coyle EF. Carbohydrate ingestion during 
prolonged exercise: effects on metabolism and performance. Exerc. Sport Sci. Rev. 1991; 19: 1-40.

10 Black AE, Coward WA, Cole TJ, Prentice AM. Human energy expenditure in affluent societies: an analysis of 574 doublylabelled water measurements. Eur. J. Clin. Nutr. 1996; 50: 72-92.

11 Westerterp KR. Alterations in energy balance with exercise. Am. J. Clin. Nutr. 1998; 68(suppl): 970S-4S.

12 Bingham SA, Goldberg GR, Coward WA, Prentice AM, Cummings JH. The effect of exercise and improved physical fitness on basal metabolic rate. Br. J. Nutr. 1989; 61: 155-73.

13 Meijer GAL, Janssen GME, Westerterp KR, Verhoeven F, Saris WHM, Ten Hoor F. The effect of a 5-month training programme on physical activity: evidence for a sex difference in the metabolic response to exercise. Eur. $J$. Appl. Physiol. 1991; 62: 11-17.

14 Blaak EE, Westerterp KR, Bar-Or O, Wouters LJM, Saris WHM. Effect of training on total energy expenditure and spontaneous activity in obese boys. Am. J. Clin. Nutr. 1992; 55: 777-82.

15 Goran MI, Poehlman ET. Endurance training does not enhance total energy expenditure in healthy elderly persons. Am. J. Physiol. 1992; 263: E950-7.

16 Westerterp KR, Meijer GAL, Janssen GME, Saris WHM, Ten Hoor F. Long term effect of physical activity on energy balance and body composition. Br. J. Nutr. 1992; 68: 2130.

17 Van Etten LMLA, Westerterp KR, Verstappen FTJ, Boon BJB, Saris WHM. Effect of an 18-wk weight-training program on energy expenditure and physical activity. J. Appl. Physiol. 1997; 82: 298-304

18 Van Baak MA, Saris WHM. Exercise and obesity. In: Kopelman PG, Stock MJ, eds. Clinical Obesity. London: Blackwell Science, 1998.

19 Davis JR, Tagliaferro AR, Kertzer R, Gerardo T, Nichols J, Wheeler J. Variations in diet-induced thermogenesis and body fatness with aerobic capacity. Eur. J. Appl. Physiol. Occup. Physiol. 1983; 50: 319-29.

20 Poehlman ET, Tremblay A, Nadeau A, Dussault J, Thériault G, Bouchard C. Heredity and changes in hormones and metabolic rates with short-term training. Am. J. Physiol. 1986; 250: E711-7.

21 Segal KR. Exercise and thermogenesis in obesity. Int. J. Obes. 1995; 19 (suppl. 4): S80-7.

22 Bahr R, Ingnis I, Vaage O, Sejersted OM, Newsholme EA. Effect of duration of exercise on post exercise $\mathrm{O}_{2}$ consumption. J. Appl. Physiol. 1987; 62: 485-90.

23 Poehlman ET, Melby CL, Goran MI. The impact of exercise and diet restriction on daily energy expenditure. Sports Med. 1991; 11: 78-101.

24 Ravussin E, Lillioja S, Anderson TE, Christin L, Bogardus C. Determinants of 24-hour energy expenditure in man. Methods and results using a respiration chamber. J. Clin. Invest. 1986; 78: 1568-78.

25 Ravussin E, Danforth Jr E. Beyond sloth-physical activity and weight gain. Science 1999; 283: 84-5.

26 Levine JA, Eberhardt NL, Jensen MD. Role of nonexercise activity thermogenesis in resistance to fat gain in humans. Science 1999; 283: 212-14.

27 Bielinski R, Schutz Y, Jéquier E. Energy metabolism during the postexercise recovery. Am. J. Clin. Nutr. 1985; 42: 69-82.
28 Bahr R, Hansson P, Sejersted OM. Triglyceride/fatty acid cycling is increased after exercise. Metabolism 1990; 39: 993-9.

29 Poehlman ET, Gardner AW, Arciero PJ, Goran MI, CallesEscandón J. Effects of endurance training on total fat oxidation in elderly persons. J. Appl. Physiol. 1994; 76: 2281-7.

30 Calles-Escandón J, Goran MI, O'Connell M, Nair KS, Danforth E. Exercise increases fat oxidation at rest unrelated to changes in energy balance or lipolysis. Am. J. Physiol. 1996; 270: E1009-14.

31 Buemann B, Astrup A, Christensen NJ. Three months aerobic training fails to affect 24-hour energy expenditure in weight-stable, post-obese women. Int.J. Obesity 1992; 16: 809-16

32 Poehlman ET, Melby C. Resistance training and energy balance. Int. J. Sports Nutr. 1998; 8: 143-59.

33 Treuth MS, Hunter GR, Weinsier RL, Kell SH. Energy expenditure and substrate utilization in older women after strength training: 24-h calorimeter results. J. Appl. Physiol. 1995; 78: 2140-6.

34 Wilmore JH. Variations in physical activity habits and body composition. Int. J. Obes. 1995; 19 (suppl. 4): S107-12.

35 Garrow JS, Summerbell CD. Meta-analysis: effect of exercise, with or without dieting, on the body composition of overweight subjects. Eur. J. Clin. Nutr. 1995; 49: 1-10.

36 Mayer J, Marshall JJ, Vitale JU, Christensen JH, Mashayki MB, Stare FJ. Exercise, food intake, and body weight in normal rats and genetically obese adult mice. Am. J. Physiol. 1954; 177: 544-8.

37 Mayer J, Roy P, Mitra KP. Relation between calorie intake, body weight and physical work: studies in an industrial male population in West Bengal. Am. J. Clin. Nutr. 1956; 4: 16975.

38 Rissanen AM, Heliövaara M, Knekt P, Reunanen A, Aromaa A. Determinants of weight gain and overweight in adult Finns. Eur. J. Clin. Nutr. 1991; 45: 419-30.

39 Williamson DF, Madans J, Anda RF, Kleinman JC, Kahn HS, Byers T. Recreational physical activity and ten-year weight change in a US national cohort. Int. J. Obes. 1993; 17: 27986.

40 Blair SN. Evidence for success of exercise in weight loss and control. Arch. Int. Med. 1993; 119: 702-6.

41 Haapanen N, Miilunpalo S, Pasanen M, Oja P, Vuori I. Association between leisure time physical activity and 10year body mass change among working-aged men and women. Int. J. Obes. 1997; 21: 288-96.

42 Schoeller DA. Balancing energy expenditure and body weight. Am. J. Clin. Nutr. 1998; 68 (suppl.): 956S-61S.

43 Van Dale D, Saris WHM, Ten Hoor F. Weight maintenance and resting metabolic rate $18-40$ months after a diet/ exercise treatment. Int. J. Obes. 1990; 14: 347-59.

44 Hensrud DD, Weinsier RL, Darnell BE, Hunter GR. Relationship of co-morbidities of obesity to weight loss and fouryear weight maintenance/rebound. Obes. Res. 1995; 3 (suppl. 2): 217s-22s.

45 Stubbs RJ, Ritz P, Coward WA, Prentice AM. Covert manipulation of the ratio of dietary fat to carbohydrate and energy density: effect on food intake and energy balance in free-living men eating ad libitum. Am. J. Clin. Nutr. 1995; 62: 330-7. 